\title{
ADRS E AS BENESSES DE MEDIAÇÃO PARA RESOLUÇÃO DE CONFLITOS AMBIENTAIS
}

\author{
Gabriel de Almeida Braga ${ }^{1}$ \\ Ícaro da Silveira Frota ${ }^{2}$
}

Resumo: O interesse por um mecanismo alternativo para solução de disputas, como eficaz substituto aos meios tradicionais de resolução de contendas, tem se demonstrado vigoroso nas últimas décadas. Na esfera ambiental, essa procura tem visado como possibilitador da integração entre meio ambiente e sociedade através de uma flexibilização e equiparação de controle de todas as - múltiplas, para além da bilateralidade - partes envolvidas em conflitos ambientais. Verificamos, através da análise realizada que, com um processo de mediação, é alcançada a resolução de conflitos ambientais de maneira efetiva, permitindo o diálogo e cooperação entre a miríade de agentes envolvidos.

Palavras-chave: Aplicabilidade; Conflitos Ambientais; Compliance; Mediação; Resolução Alternativa de Disputas.

\section{ADRS AND THE BENEFITS OF MEDIATION TO RESOLVE ENVIRONMENTAL CONFLICTS}

\begin{abstract}
The interest in an alternative mechanism of dispute resolution, as an effective substitute for the traditional dispute resolution means, has shown itself to be vigorous in recent decades. In the environmental sphere, this demand has been aimed at enabling integration between the environment and society through flexibility and equal control of all multiple, in addition to bilaterality - parties involved in environmental conflicts. We verified, through the analysis carried out that, with a mediation process, the resolution of environmental conflicts is achieved in an effective way, allowing dialogue and cooperation among the myriad of agents involved.
\end{abstract}

Keywords: Applicability; Environmental Conflicts; Compliance; Mediation; Alternative Dispute Resolution.

\section{INTRODUÇÃO}

A busca por modelos alternativos de resolução de conflitos atingiu seu apogeu após constantes tentativas de refrear o fluxo de ações propostas em tribunais de justiça e de conceber mecanismos mais ágeis e baratos, tendo como resultado o surgimento da conciliação,

\footnotetext{
${ }^{1}$ Advogado, Mestrando no Programa de Pós-Graduação em Direito Ambiental da Universidade de Caxias do Sul, área de concentração Direito Ambiental e Sociedade. Graduado em Direito pela Universidade de Caxias do Sul.gabraga@ucs.br.

${ }^{2}$ Advogado, Mestrando no Programa de Pós-Graduação em Direito da Universidade de Caxias do Sul, área de concentração Direito Ambiental e Sociedade. Especialista em Direito Previdenciário (Escola da Magistratura Federal - ESMAFE) e Direito Material e Processual do Trabalho (Universidade de Caxias do Sul). Graduado em Direito pela Universidade de Caxias do Sul. isfrota@ucs.br.
} 
arbitragem e - sua opção de maior sucesso e procura - a mediação (HILL, 2020). Essa jornada, conforme veremos, foi tortuosa, com a presença de procedimentos semelhantes aos atualmente glorificados sendo encontradas em registros que datam mais de três mil anos, esquecidos no tempo diante do interesse em burocratizar os mecanismos e desequilibrar o controle dentre as partes envolvidas nos conflitos, pendendo sua balança para a lado do Estado (BERLIE, 2017). Essa desarmonia refreia o caminhar para a consubstanciação de decisões justas, especialmente em conflitos ambientais que, repletos de peculiaridades que o tornam complexos como é o caso de sua multicausalidade, pluralidade de atores e incertezas cientificas, necessitam de maior liberdade para a conversação entre as partes. Essa preocupação tem se tornado centro de estudos acadêmicos que intentam procurar configurações voluntárias e espontâneas,

distantes da estruturação encontrada em tribunais (SILVA, 2017).

A resolução de disputas por vias não judiciais - alternativas - que aproximam as partes e tratam de identificar e reconhecer as particularidades de suas individualidades e da contenda em que estão envolvidos permite que sejam reforçados princípios fundamentais e que sejam mais facilmente alcançados objetivos de resguarda ambiental e pacificação social A mediação, por este ângulo, incentiva a atuação ativa e cooperativa dos conflitantes iniciais e daqueles que entenderem que são ou serão prejudicados por estes conflitos ambientais, incluindo-se (in)diretamente as gerações futuras e populações que desconhecem totalmente o que se está debatendo e como isso pode afetá-los (CASELLA; SOUZA, 2009).

Contando com este pano de fundo teórico o presente artigo possui, como justificativa, a imprescindibilidade da admissão e alastramento de métodos alternativos para resolução de conflitos ambientais que, se omitindo ou silenciando uma ou mais partes relacionadas, maiores impactos - possivelmente irreversíveis - do que os inicialmente esperados pelos julgadores serão recebidos, sem que possamos garantir com segurança que a sobrevivência dos recursos ambientais e vida dos habitantes da biosfera será resguardada.

Assim, ante o interesse em colher um conhecimento bem desenvolvido sobre a temática em questão, investigaremos no presente artigo o surgimento dos métodos alternativosde resolução de disputas e o êxito da mediação, passando posteriormente à análise da aplicação desta exclusivamente para a matéria ambientais, verificando os elementos intrínsecos aos conflitos ambientais, a ascensão e desenvolvimento regulatório da mediação no Brasil ebenesses deste mecanismo para a conquista de decisões reciprocamente aprováveis. Levando isto em consideração, foi traçado o seguinte problema de pesquisa: Em 
que medida a mediação é capaz de satisfazer os interesses e necessidades que rodeiam os conflitos ambientais?

Como hipótese principal, temos que através de um adequado processo de mediação são consolidadas formas efetivas de cooperação e diálogo entre a miríade de agentes envolvidos em conflitos ambientais, valendo-se de aspectos característicos deste mecanismo como a flexibilidade e celeridade para abarcar as características únicas dos conflitos ambientais que dificultam sua resolução através de meios tradicionais.

O objetivo geral é o de demonstrar as benesses da mediação para resolução de conflitos ambientais, sendo os objetivos específicos o de observar como surgiu e por qual motivo houve a disseminação da mediação, assim como expor as complexidades que envolvem estas disputas e as benesses de utilização deste mecanismo que recebeu destaque no presente século. Para tanto, este artigo foi realizado através do método de pesquisa de revisão de literatura narrativa descritiva com abordagem teórica, apoiando-se em fontes bibliográficas diversas relacionadas ao tema, principalmente as de autoria de especialistas e profissionais, orientadas para que apresentem a estrutura teórica e base para postulações pertinentes. Para a coleta de dados foi realizada a seleção de artigos, periódicos científicos, livros físicos e digitais.

\section{ALTERNATIVE DISPUTE RESOLUTION (ADR) E A DISSEMINAÇÃO}

\section{DA MEDIAÇÃO}

Solução de conflitos, por si só, é uma terminologia ampla que dá um sentido genérico para o que se busca alcançar, comportando um longo leque de possibilidades que podem envolver métodos coercitivos, não sendo de nosso interesse analisar ou sugerir o emprego de métodos violentos para lidar com conflitos (PINHO, MAZZOLA, 2019). Sua resolução deve se dar de modo a solucionar as divergências implícitas ao conflito, o que pode incluir a tratativade fazer uma ou múltiplas partes reconhecer a existência da outra e fazê-las entender o motivopor trás deste processo que está se realizando.

A idealização de um método de solução de conflitos que, além de se realizar fora das vias judiciais, emprega a figura de um terceiro como moderador não é algo estrito ou tradicional ao território nacional brasileiro, tendo o interesse em sua utilização aumentado consideravelmente nas últimas décadas para as mais variadas áreas e conflitos, tendo como atrativo inicial a celeridade e equilíbrio de interesses quando comparado aos métodos 
tradicionais (HILL, 2020).

Essa euforia para identificar métodos de resolução alternativa de disputas (Alternative Dispute Resolution - ADR) tem origens múltiplas, como o interesse do judiciário em reduzir seu fluxo de ações, garantia de observação e potencialização do direito fundamental de acesso à justiça, fortemente defendida pela doutrina que entusiasticamente promove-a como um eficaz mecanismo de acesso à justiça. Tomadores de decisão e empreendedores do setor empresarial (SCHABBEL, 2007) tem na mediação uma possibilidade de redução de custos e resolução amigável de conflitos que podem trazer grandes prejuízos aos envolvidos caso esse enfrentamento seja deixado de lado ou veja o seu esgotamento nas vias judiciais (CASELLA; SOUZA, 2009; FILPO, 2016).

Sua recepção na via comunitária (AL, 2019) demonstrou ser uma opção apta a intensificar o acesso à justiça em comunidades, sendo argumentado que uma adequada capacitação - como a realizada pelo Tribunal de Justiça de Alagoas (2009) - de líderes comunitários e demais pessoas engajadas em atividades nas regiões serve como medida preventiva de atos violentos, reduzindo o número de casos em que a intervenção estatal se faránecessária.

Dito isso, resta evidente que, não obstante a pluralidade de cenários de aplicação, é existente uma equivalência estrutural e ideológica para esta modalidade de ADR, compartilhando em sua essência o desejo por uma solução consensual e pacífica. A resolução alternativa de disputas teve como mecanismos iniciais a conciliação, mediação e arbitragem, tendo nos últimos anos incorporado uma panóplia de opções e alternativas autônomas e um tanto atípicas. Se passarmos a considerar estas modalidades diferenciadas como uma ramificação dos mecanismos ADR, a mediação - juntamente da arbitragem e conciliação - em sua conceituação ampla pode ser considerada a base de orientação para a propagação de novas alternativas (RODRIGUES, 2009).

Episódios como o que estamos vivenciando, com a consolidação da mediação no ordenamento jurídico através da Lei $n^{\circ}$ 13.140/2015, trouxeram consigo preocupações e debates acalorados em torno da profissionalização de mediadores e conciliadores. Concomitantemente, o surgimento destes profissionais e suas variações - conforme o setor que desejam atuar direciona os interessados à questões, sobre sua padronização de condutas e criação de códigos de ética, imposição ou não de qualificações responsabilização, avaliação e outros fatores que ao serem analisados não podem fazer com que se esqueça a finalidade primordial destes 
indivíduos (SIVIERO, 2015).

A repercussão positiva da mediação traz, ainda, indagações referentes à agilidade com a qual estudos sobre a temática estão sendo realizados e como o desenvolvimento desta prática vem ocorrendo em âmbitos e circunstâncias - à primeira vista - discordantes, sendo uma explicação plausível a de que estes mecanismos e seus conhecimentos acessórios não são tão recentes quanto as exposições da atualidade fazem crer (ROEBUCK, 2007).

Destarte, embora existente um pertinente sentimento de inovação e modernidade em relação aos ADRs, a realidade não corresponde com está expectativa, sendo a resolução de conflitos por vias não judiciais algo inerente à inúmeras culturas, com mecanismos seculares que em muito se assemelham à forma da mediação moderna. Da Silva (2013) esclarece que este conceito de intervenção de um terceiro para auxiliar em uma disputa se faz presente muito antes da consolidação de sistemas jurídicos e de figuras como as dos julgadores e dos causídicos, não se desmerecendo o fato que a aplicação destes mecanismos na contemporaneidade se deu com maior veemência somente nas últimas décadas, quando tratativas internacionais e nacionais, especialmente nas de cunho econômico, viram nestas alternativas o discernido caminho que há tempos procuravam, esquecendo ou até mesmo ignorando ensinamentos passados.

Para melhor visualização e esclarecimento iremos nos direcionar ao exemplo mesopotâmico de mediação, quando há aproximadamente quatro mil anos atrás o Rei de Kish (BERLIE, 2017) exerceu função de mediador em um conflito cujo objeto a posse de terras sumérias, tendo sua participação possibilitado uma resolução pacífica que, ao mesmo tempo que evitou enfrentamentos violentos, recebeu o reconhecimento como um dos - senão primeiro - caso de mediação registrada na história.

Em seu formato mais restrito, as ADRs são reconhecidas como um conjunto de mecanismos de resolução de disputas/conflitos que complementam os métodos tradicionais e formais de solução de controvérsias, não possuindo primariamente o condão substitutivo aos sistemas de adjudicação. Não obstante, as ADRs tanto em literatura estrangeira (MOORE, 2014) quanto nacional (SIVIERO, 2015) possuem aqueles processos centrais já referidos, quais sejam a mediação, objeto deste estudo cuja característica de distinção está na existência de um terceiro que auxilia no diálogo entre os agentes, a conciliação e o terceiro apto e autorizado à oferecer soluções e a arbitragem, onde este terceiro possui a responsabilidade para definir qual será a decisão final para o conflito, distinção está que é esclarecida com maestria por Da Silva (2013). 
A etapa de negociação é elemento em comum entre os mecanismos de ADRs, centralizando a ideia de que os interesses de ambas as partes envolvidas devem ser equiponderados, sendo tarefa na mediação tradicional a de explanar às partes os pontos e contrapontos da disputa, articulando durante desentendimentos para melhor fazê-las compreender o que está em desacordo, auxiliando-os para que encontrem por si só a solução que melhor atende às suas necessidades (SIVIERO, 2015).

Divergências de abordagens não são incomuns, com a introdução de peculiaridades como revisões, exigências específicas, penalidades por má-fé e demais elementos que dão personalidade e aumentam a aceitação e eficácia do procedimento, dependendo dos costumes e cultura locais, não se omitindo diretrizes, normas e princípios norteadores dos ADRs. Sua finalidade não é modificada mesmo com a presença destas variações, mantendo-se o foco na facilitação e resolução dos impasses (ROEBUCK, 2007; DA SILVA, 2013).

A negociação pode, então, ser entendida como a ampliação das alternativas e, consequentemente, a solução de conflitos multifacetados em um único momento. Expondo outro ponto de vista, Moore (2014) analisa as combinações de disposições entre as partes, relatando as disparidades de oportunidades de manifestação que muitas vezes ocorrem nesta etapa sob a supervisão de terceiro despreparado. Refere que ao intermediário é devido reconhecer a postura tomada pelas partes e adotar a aproximação que melhor couber para aquele tipo de ADR que se escolheu, tornando todo o processo de resolução algo mais humanizado e social, essência das negociações modernas.

Retomando o foco à mediação, esta parece ter recebido a aprovação social e legal apenas recentemente, sendo vista como uma atividade até então não legitimada e fiscalizada, pouco reconhecida como uma alternativa aos métodos tradicionais. Contudo, a formalização de processos de capacitação de indivíduos a tomarem a posição de intermediadores em negociações foi inserida em cursos ministrados em universidades americanas na década de 70 , inicialmente vinculados ao âmbito dos estudos jurídicos, sendo poucas vezes objeto de interesse (PINHO; MAZZOLA, 2019).

Se pode sugerir, de certa maneira, que a disseminação de mecanismos alternativos de resolução de conflitos se deu em grande parte reconhecimento social e estatal de que estes possuem qualidades que possibilitam que sua utilização seja indicada em situações que até então só tinham como solução o ingresso nas vias judiciais (SIVIERO, 2015).

O que vem se (re)descobrindo em estudos atuais é que muitos destes cenários que eram 
vistos como o de embates antagônicos, onde apenas um participante sai como vencedor, são em verdade situações negociáveis, com a possibilidade de atender aos clamores de ambos, desde que devidamente acompanhados por uma pessoa capacitada para lhes auxiliar (FILPO, 2016).

A idealização de uma resolução mediada vem a suceder a conceituação de julgamento instituído como a alegoria inspiradora da solução de conflitos. Isso posto, se o paradigma contemporâneo do gerenciamento de conflitos está voltado para as negociações amigáveis dos participantes da disputa, a mediação e sua pletora de formatos e situações de aplicação é melhor entendida como o agrupamento de processos de negociação (PINHO; MAZZOLA, 2019).

De modo geral, em maior ou menor escala, as técnicas de mediação buscam, através de um correto aproveitamento dos recursos e permissões ao seu alcance, instigar e potencializar a ocorrência de momentos férteis para a troca de opiniões e interesses que oportunizem a solução pacífica e harmônica do problema debatido, enfatizando que este mecanismo de ADR oferece um processo sem preconceito.

\subsection{MEDIAÇÃO - UM PROCESSO SEM PRECONCEITO}

Os ADRs em geral têm como característica basilar de seus procedimentos a ausência de preconceitos, sendo dever do terceiro - conciliador, mediador, arbitro... - exercer sua função com imparcialidade, ciente e sensível às idiossincrasias de cada parte sem que seja dado tratamento diferenciado à uma destas. Este ponto é de tamanha importância para este mecanismo que é devido neste momento esclarecer qual o significado de um processo/procedimento sem preconceitos, tarefa mais bem executada ao se aplicar como base ensinamentos como o de Almeida (2016) e seu estudo sobre a mediação social e outros autores que estudam a fragilidade do emprego da mediação em cenários como o ambiental (DE FREITAS; AHMED, 2016).

Em juízo as provas, respeitados os requisitos legais, serão produzidas, recebidas e avaliadas dentro daquele processo em específico, com sua replicação em outros meios permitida somente perante justificativa e autorização do magistrado, o qual julgará a lide imparcialmente, sem considerar qualquer conceito prévio que possa intervir em sua decisão, sendo a atividade jurisdicional - neste sentido - sem preconceitos.

É indispensável ao sistema jurídico que as partes apresentem suas provas, ainda que 
haja imposição de uma série de restrições a serem observadas, não baseadas em simples preconceito, mas fundamentadas em princípios de justiça, auxiliando na manutenção de uma sociedade, nos termos do preâmbulo constitucional, "sociedade fraterna, pluralista e sem preconceitos, fundada na harmonia social e comprometida, na ordem interna e internacional, com a solução pacífica das controvérsias” (BRASIL, 1988), mensagem que, indiretamente, alberga mecanismos como os ADRs.

Este caráter, de ser sem preconceito, é fator de interesse à realização da mediação, momento em que qualquer forma de discriminação pode acarretar o desrespeito ao direito de acesso à justiça e, simultaneamente, reduzir as chances de se solucionar o conflito de maneira não violenta ou morosa, sendo incentivado que estes mecanismos recebem tratamento semelhante ao conferido às atividades jurisdicionais (PINHO; MAZZOLA, 2019).

\section{MEDIAÇÃO AMBIENTAL}

Parcela majoritária da doutrina brasileira analisa a mediação ambiental sob a ótica das Leis $\mathrm{n}^{\mathrm{o}} 13.105 / 2015$ e $\mathrm{n}^{\mathrm{o}} 13.140 / 2015$, havendo poucos estudos de casos detalhados e que comportem teoria e prática em sua pesquisa, sendo o mais recente que preenche tais requisitos o artigo produzido por De Araújo et al. (2020), adotando a mediação para resolução de conflitos relacionados aos recursos hídricos da Bacia do Rio Sergipe.

Críticas desta prática na seara ambiental são encontradas em obras (CAMPBELL; FLOYD, 1996) não tão recentes, mas não menos importantes, sobre os desafios e complicações envolvendo este mecanismo, salientando a cautela que deve se ter ao aplicar tais procedimentos, não se olvidando de fatores como a proteção do interesse público, admissão de grupos ambientais, saúde e segurança socioambiental e possíveis disparidade de poderes que possam ter efeitos negativos que extrapolam uma mera falha em alcançar resoluções de conflitos ambientais.

As opções de mecanismos ADR são muitas, conforme visto anteriormente, abrangendo processos em que solução é imposta por um terceiro - arbitragem - ao invés de ter a participação das partes envolvidas no processo decisório e aqueles como a mediação, com o terceiro envolvida exercendo função auxiliar, buscando um consentimento mútuo daqueles que se encontram no núcleo do conflito (BRAGA NETO et al., 2019). Este último grupo possui uma gama de métodos em que o terceiro auxiliar pode apresentar um posicionamento mais ativo 
ou neutro, agindo para tão somente garantir que o respeito mútuo às partes e as regras preestabelecidas está sendo mantido ou, a opção mais popular para a maioria dos setores, a da figura de um interventor diplomata, mediando o equilíbrio de controle exercido pelas partes (MOORE, 2014).

Na esfera ambiental, a mediação apresenta benefícios que permitem a otimização dos procedimentos para melhor atender à conflitos únicos, com peculiaridades que, se observadas, possibilitam a resolução cooperativa e pacífica. O mediador não apresentará as soluções, mas esclarecerá quaisquer obscuridades que surgirem durante o procedimento, amparando as partes a vencer o histórico de eventos negativos que tenham marcado a relação de ambas, incentivando-as solucionar de maneira cooperativa o conflito, expandindo suas expectativas e negociando as medidas a serem tomadas para que todos obtenham um resultado desejável (SILVA, 2017).

As dificuldades de se obter resultados positivos está na singularidade dos conflitos ambientais, devendo estes serem observados para que se possa usufruir de seus benefícios, não sendo uma estruturação genérica recomendada diante da impossibilidade de se atender de maneira eficaz todos os conflitos da mesma forma. O interesse estatal em encorajar a predominância destas alternativas e garantir seu sucesso está representado pela promulgação de diplomas legais como a Lei 13.140/2015.

\subsection{CONFLITOS AMBIENTAIS E AS DIFICULDADES PARA SUA} RESOLUÇÃO

Os conflitos ambientais são fenômenos multicausais e multifacetados, dificultosamente conceituados em termos ou perspectivas que tenham aplicação absoluta para qualquer cenário, sua existência é um resultado natural da coexistência de agentes com pensamentos e prioridades divergentes (ACSELRAD, 2014). Semelhantemente a outros processos sociais, os conflitos ambientais não encontram resolução de maneira autônoma, sendo o resultado da não intervenção um processo violento e destrutivo, com impactos que superam a esfera dos envolvidos e passam a comprometer direitos de terceiros. É um empecilho volátil, com sentido indicado pela especificidade dos fatores que o compõem, pelo número de atores incluídos, seu relacionamento com as partes contrárias e pela quantidade de desconhecidos que são - e serão - afetados (SILVA, 2017). 
Por serem o centro de debates científicos e políticos os conflitos ambientais foram por muitos anos diretamente arrastadas ao sistema judicial em busca de uma solução aceitável, não surpreendendo a dificuldade encontrada pelo Judiciário para distinção e classificação de evidências científicas discrepantes. Mesmo que justas, as decisões legais em muitos casos acabam não atendendo os interesses de ambas as partes e prováveis afetados, sendo a preservação do bem-estar e paz social, apáticas às preferencias dos envolvidos, não atingindo a efetividade de uma mediação ambiental (SIVIERO, 2015; BRAGA NETO et al., 2019).

Em conformidade com Silva (2017, p. 80) "a dificuldade desses conflitos de esfera pública está na complexidade da matéria, na capacidade de respeitar as diversidades e os interesses de múltiplos envolvidos e o contexto em que se insere.”. Refere que os conflitos ambientais abarcam peculiaridades que a tornam uma matéria complexa, multi/interdisciplinar e que excede as barreiras territoriais, sendo impossível à via judicial, ante sua inflexibilidade, morosidade e formalismo, apresentar soluções que abarquem os múltiplos interesses envolvidos, sendo a mediação uma alternativa célere e eficaz, habilitada para realizar tais feitos a mediação.

Desmistificando o conflito ambiental são elencados os elementos que dão peso à alegação da sua complexidade, iniciando-se pela multilateralidade representada pela amplitude e diversidade de atores que, com níveis variados de participação, por vezes não são facilmente identificados com uma análise inicial do conflito que aflorou. A má estruturação/limitação de políticas públicas e os consequentes impactos de atividades antropogênicas tem como um de seus fatos causadores a capacidade destes efeitos nocivos ao meio ambiente conseguirem se disseminar e transpassar territórios ao longo do tempo. Em resposta, gradativamente novos atores são direta ou indiretamente afetados por decisões e incluídos em decisões ambientais que podem ter consequências de longo alcance, que, devido à sua publicidade, atraem novos indivíduos à contenda (ACSELRAD et al., 2014; BRAGA NETO et al., 2019).

Através desta pluralidade de atores mais de um destes pode arguir que o seu entendimento representa o interesse público social, embasando seu posicionamento em questões humanitárias, comunitários e/ou de gerações futuras e outras justificativas que, do seu ponto de vista, elevam seus interesses a um patamar superior ao dos demais participantes, restando ao julgador a difícil tarefa de apreciar estes apontamentos e apresentar uma decisão imparcial e justa.

Nesta senda, Silva (2017) reitera o argumento sobre a complexidade dos conflitos 
ambientais contemporâneos, cenários onde locais distantes do ponto de origem da problemática são passiveis de sofrer seus efeitos, desrespeitando barreiras territoriais e trazendo para si novos atores. A dimensão geográfica e caráter mediático suscitado por estes conflitos transcende a esfera regional e cria uma indesejada ponte entre o local e o global, propagando disputas internas, insegurança ambientais e interesses que acabam por envolver múltiplas culturas, sociedades e ambientes.

Ademais, agências - ambientais - reguladores fazem parte, na maioria dos casos, dos conflitos ambientais, dificultando o equilíbrio entre as partes, sendo o seu desinteresse e hostilidade muitas vezes justificado pela possibilidade de estas agirem de modo individual e parcial, desconsiderando a magnitude do problema enfrentados.

Atribulações estas que em determinadas ocasiões compreendem questões de grande complexidade e/ou incerteza científica, com efeitos de magnitude e duração desconhecidas e possivelmente irreversíveis. Tamanha é a apreensão do direito ambiental com estes fatores que as intervenções são norteadas por princípios como o da precaução, sendo devido tomar decisões que, em caso de dúvida, busquem resguardar os bens ambientais.

Um excelente exemplo do interesse e preocupação do meio acadêmico com as incertezas científicas e a proteção ambiental é facilmente reconhecido pelo registro de Berger Filho (2009) ao declarar que: "princípio da precaução é justificado pela necessidade de tomada de decisão antecipada, mesmo se opondo a forte pressão por crescimento econômico e pelo desenvolvimento da ciência e tecnologia com vistas ao mercado.”. Em apartada síntese, os problemas ambientais da atualidade estão envoltos por dúvidas acerca da certeza cientifica de seus efeitos, cabendo ao Direito a implementação de mecanismos agilizem e aumentem a eficácia de soluções mesmo em casos de conflitos ambientais que abarcam incertezas científicas, sendo a mediação a opção mais coerente para identificar e manejar estas peculiaridades.

\subsection{EVOLUÇÃO REGULATÓRIA DA MEDIAÇÃO BRASILEIRA E A NOVA LEIDE MEDIAÇÃ̃}

Seguindo tendências mundiais de revisitar o passado e apresentá-lo como novo o Brasil se propôs, nos anos 90, a enfrentar o desafio de elaborar novos mecanismos e instrumentos que 
possibilitem às partes uma equidade de controle e maior possibilidade de participação ativa na resolução de conflitos. Com esse objetivo em consideração se iniciou uma restruturação governamental para o fim de instruir e estimular a população em geral a buscarem métodos consensuais e pacíficos para solucionar os conflitos, havendo a mediação recebido destaque com o estabelecimento do CONAMA no final da referida década e diplomas legais promulgados à época para a regulamentação desta modalidade de ADR (BRAGANÇA; SOUZA, 2017).

Posteriormente, já no século XXI, novas tratativas foram realizadas para a promoção de novos mecanismos, contando com a aprovação da Emenda Constitucional de número 45/04 para promover os princípios de acesso à justiça e razoável duração processual, vindo a mediação a receber efetiva menção e regulamentação no ano de 2010, com o surgimento de nova resolução - no 125/10 - do CNJ e posterior alteração em 2013 (SIVIERO, 2015; SILVA, 2017). Mais recentemente, restou promulgada a Lei $\mathrm{n}^{\mathrm{o}} 13.140 / 2015$, diploma responsável por representar um legítimo quadro jurídico da mediação, prevendo suas principais variações e cenários de aplicação, sendo um ponto merecedor de destaque o incentivo e indicação da execução destes mecanismos para resolução de conflitos que tem como uma das partes envolvidas a administração pública. Nela, há previsão das modalidades extrajudiciais e judiciais de mediação, havendo restrições para o exercício da função de mediador no âmbito judicial

(DOS ANJOS JUNIOR et al., 2020).

As disposições de maior relevância ao tema, conforme De Freitas e Ahmed (2010), são aquelas que tratam da resolução de conflitos que envolvem particulares e a administração pública através de mecanismos alternativos e facultativos, favorecendo a eficácia da tutela ambiental e aprimorando o gerenciamento de questões socioambientais por vias de maior aceitação e que permitem maior interação entre o Estado e sociedade. Ainda, no tocante à possível arguição de impossibilidade de aproveitamento de métodos não judiciais de resolução de conflitos ambientais, por envolverem direitos indisponíveis, o próprio diploma é claro ao expressar está possibilidade, demonstrando o cuidado do legislador em potencializar a proteção do meio ambiente.

\subsection{BENEFÍCIOS}

Conflitos ambientais apresentam certo grau de complexidade, com disputas que 
envolvem tópicos de extrema relevância ambiental, social, econômica e cultural que afetam o equilíbrio na relação humanidade - meio ambiente, tendo como os atores envolvidos uma variedade de opiniões, crenças e conhecimentos que merecem atenção para suas disputas mantenham-se na esfera da resolução voluntária e pacífica.

Para que haja equilíbrio e maior sucesso nas tentativas de solucionar conflitos ambientais Freitas (2017) argui em seu estudo que a postura hostil exibida pelo Estadoadministração durante negociações ofusca as pretensões de solucionar conflitos de maneira pacífica e cooperativa, impede o controle equitativa das partes e prejudica os interesses públicos de proteção de bens ambientais, apresentando ainda efeitos negativos que são contrários aos princípios constitucionais brasileiros. Cita a possibilidade de aplicação de métodos alternativos - como a mediação - para a resolução de conflitos, sinalizando apenas que tais mecanismos devem ser realizados com determinado nível de organização e regramentos, ante sua relevância e impacto na sociedade.

Mediar embates com temas tão importantes não são, por todo o exposto, tarefa fácil, o que sugere a existência de benefícios ou vantagens que estimulem sua realização e justifiquem o esforço despendido. Analisando a mediação ambiental Silva (2017) indica alguns dos pontos positivos desta prática em substituição dos métodos tradicionais e jurídicos de solução de conflitos. O primeiro destes, o da flexibilidade - procedimental, diz respeito à capacidade deste mecanismo de se adequar à cada caso em particular, sem preconceitos sobre aquilo que deve ser feito ou sobre as partes que estão envolvidas no conflito a ser solucionado. Siviero (2015) já apresentavam entendimento semelhante, arguindo que este elemento é essencial para a resolução eficiente de um conflito, mormente em situações em que há forte divergência cultural entre os envolvidos.

A maximização de interesses é outra benesse da mediação ambiental, sendo de certo modo uma consequência da flexibilidade, podendo o mediador valer-se - ponderadamente - de sua criatividade para melhor responder aos requerimentos dos envolvidos, determinando quais os temas são essenciais para cada partícipe do conflito, qual o inventário de interesses destes e suas necessidades, para então definirem os termos finais da mediação (SILVA, 2017).

O empoderamento das partes através do controle - equitativo -a ser aproveitada para a mediação é outro benefício constatado, visto que as vias tradicionais têm sua estrutura procedimental engessada em termos preestabelecidos em lei. A liberdade e autonomia conferida durante a mediação ambiental permite ao mediador e os envolvidos considerarem opções não 
cogitadas em outros meios, estando elas com o controle de suas decisões, não podendo ser impostas a elas qualquer termo que estas não concordarem.

Sem embargo de que Pinho e Mazzola (2019) dediquem seu estudo exclusivamente à mediação ambiental, suas técnicas de mediação demonstram o forte potencial da equivalência de participação e controle dos principais atores sobre a disputa e o processo de resolução. Dos seus ensinamentos se depreende que não há como uma parte ser bem recebida e suas exposições consideradas pela outra se essa possui maior autoridade ou poderes do que sua contraparte, tendo na equidade, além de um tratamento justo, uma maior demonstração de predisposição de alcançar um resultado positivo amigavelmente.

A preservação da pacificação social, a quarta vantagem da mediação ambiental segundo Silva (2017), tem seu lugar no rol apresentado pela autora para o fim de esclarecer e incentivar a resolução de conflitos através de métodos alternativos, visando o aumento da consciência sobre debates que envolvem a resguarda ambiental, preservação de recursos naturais e enfatizando a relação entre a saúde e qualidade de vida humana, o meio ambiente e os demais habitantes da biosfera, evitando o contencioso ambiental e se encaminhando à pacificação social com a conscientização ambiental.

Destaca, ainda, a relação entre esta vantagem e a anterior, sendo possível a busca pela paz social somente em situações em que há equilíbrio entre as partes envolvidas em um conflito, não podendo se esperar que o meio ambiente se beneficie de mecanismos como a mediação caso não a pacificação social não for um dos objetivos buscados. O quinto e último benefício, o da redução de custos e tempo de resolução é objeto de estudo e destaque de diversos autores, não se consequência específico à mediação ambiental, mas à mediação de maneira geral.

O custo para a resolução de conflitos através da via judicial é responsável por gerar um obstáculo ao acesso à justiça, estipulando muitas vezes se as partes buscarão uma solução pacífica e legal ou se prosseguirão mantendo a disputa paralisada em um estado de desacordos constantes, encontrando na mediação uma alternativa viável para a tentativa de um diálogo saudável e pacífico sobre um problema que em muitos casos transcende a esfera pessoal (CASELLA; SOUZA, 2009).

Da ótica da administração pública, conflitos ambientais geralmente envolvem questões de elevado risco e impacto ambiental, econômico e social, cujo resolução afetará - positiva ou negativamente - um elevado número de pessoas e/ou envolverá quantias consideráveis de recursos dos cofres públicos. A mediação como meio de resolução de conflitos ambientais 
proporciona uma redução de custos e, conjuntamente, uma redução de recursos judiciais e de recursos humanos ao se optar por uma alternativa consideravelmente mais ágil do que o processo judicial.

\section{CONSIDERAÇÕES FINAIS}

Neste estudo observamos o desenvolvimento das alternativas de resolução de disputas e a ascensão da mediação como uma opção coerente para solucionar os conflitos ambientais de uma maneira pacífica e cooperativa. Verificamos que este mecanismo é livre de preconceitos, proporcionando o aperfeiçoamento interpessoal dos envolvidos na contenda, contando com a presença de um terceiro - mediador - de confiança e capacitado para auxiliar as partes durante seu diálogo e apresentação de interesses, suscitando o desenvolvimento de uma consciência harmônica e ecológica.

Reconhecemos durante nossa revisão de literatura que a existência de mecanismos não é recente, retomando culturas e povos de milênios atrás para encontrar indícios das intervenções de terceiros para solucionar conflitos e instigar a manutenção da paz social. Depreendemos destas leituras que estes conhecimentos e práticas se perderam no tempo, retomando à realidade social somente em meados do século XX, sendo o caso brasileiro um tanto atardado, tomando formas capazes de ampliar a resguarda do meio ambiente somente a partir dos anos 90 e, com maior intensidade, no ano de 2015 com a promulgação de legislação específica para regulamentar a mediação e abarcar os conflitos ambientais.

Analisamos as peculiaridades da mediação ambiental, identificando as dificuldades enfrentadas para o gozo dos benefícios que ela pode oferecer à sociedade e meio ambiente, enfrentando polêmicas envolvendo a morosidade das vias judiciais em matéria ambiental e as complexidades dos julgadores em apresentar uma decisão que reconheça as necessidades, as incertezas cientificas de cada caso e os interesses de todos os envolvidos, bem como apresentam custos que por muitas vezes vão contra o princípio de acesso à justiça.

Isto posto, entendemos que a mediação se consolida como uma alternativa indicada para o fim de possibilitar o alcance de uma solução justa para as disputas ambientais, aproveitando-se de suas características de equiparação de partes, voluntariedade e maximização dos interesses para garantir que todas as partes terão oportunidades iguais de apresentar seus posicionamentos e motivações. 
Essa, de certo modo, liberdade concedida às inúmeras partes auxilia a administração pública a atingir seu fim de preservar os recursos ambientais e o surgimento de novos problemas subsequentes, que em muitos casos afetariam sujeitos para além de seus territórios e competência, agregando um aspecto pedagógico aos procedimentos de resolução de conflitos, incitando maior comprometimento estatal e da sociedade em geral.

Por fim, no tocante à aplicação deste mecanismo no Brasil, acreditamos ser coerente arguir que estamos nos direcionando no caminho correto, sendo não apenas viável, mas sim uma alternativa plenamente capaz de atender aos interesses e necessidades dos múltiplos atores relacionados aos conflitos ambientais. Resta, como sugestão, a realização de novos estudos para verificação da efetiva capacidade estrutural do país em propiciar ambientes onde as mediaçõespossam ser realizadas, uma vez que evidente - dentre outros benefícios - aptidão deste meio em entregar soluções de maneiras mais céleres e com menores custos, ampliando o acesso à justiça.

\section{REFERÊNCIAS}

ACSELRAD, Henri et al. Conflitos ambientais no Brasil. Relume Dumará, 2014.

AL, Mônica Abdel. A mediação comunitária no Brasil: um diálogo com o pluralismo jurídicocomunitário-participativo. 2019.

BERGER FILHO, Airton Guilherme. Nanotecnologia e o princípio da precaução na sociedadede risco. Revista Jus Navigandi, ISSN 1518-4862, Teresina, ano 14, n. 2359, 16 dez. 2009. Disponível em: https://jus.com.br/artigos/14019. Acesso em: 7 dez. 2020.

BERLIE, Jean A. Chapter-6 Uncitral Arbitration Rules To Resolve Commercial Disputes Along The New Silk Road Of China. ICSID Review, v. 625, 2017. p. 672.

BRAGA NETO, Adolfo et al. Negociação, mediação, conciliação e arbitragem: curso de métodos adequados de solução de controvérsias. 2019.

BRAGANCA, Fernanda; SOUZA, Carla Faria de. As etapas de institucionalização da mediaçãono Brasil. Revista de Formas Consensuais de Solução de Conflitos, v. 3, n. 1, p. 01-15, 2017. 
BRASIL. Constituição Da República Federativa Do Brasil De 1988. 1988. Disponível em http://www.planalto.gov.br/ccivil_03/constituicao/constituicaocompilado.htm Acesso em: 03 dez. 2020.

CAMPBELL, Marcia Caton; FLOYD, Donald W. Thinking critically about environmental mediation. Journal of Planning Literature, v. 10, n. 3, p. 235-247, 1996.

CASELLA, Paulo Borba; SOUZA, Luciane Moessa de. Mediação de conflitos: novo paradigma de acesso à justiça. 2009.

DE ARAÚJO, Vanessa Gomes et al. The use of conflict mediation by the Sergipe River Basin Committee as a tool for implementing decentralised water resource management. InternationalJournal for Innovation Education and Research, Vol. 8 No. 9, 2020.

DE FREITAS, Gilberto Passos; AHMED, Flavio. A mediação na resolução de conflitosambientais. 2016.

DOS ANJOS JUNIOR, José Camilo et al. A COMPLEXIDADE DA MEDIAÇÃO SOCIOAMBIENTAL SOB A ÉGIDE DA LEI N ${ }^{\circ} 13.140 / 15$. Revista Brasileira de Direito eGestão Pública, v. 8, n. 2, p. 476-487, 2020.

FILPO, Klever Paulo Leal. Mediação judicial. Mauad Editora Ltda, 2016.

FREITAS, Juarez. Direito administrativo não adversarial: a prioritária solução consensual deconflitos. Revista de Direito Administrativo, 2017.

HILL, Flávia Pereira. PASSADO E FUTURO DA MEDIAÇÃO: PERSPECTIVA

HISTÓRICA E COMPARADA. Revista de Processo| vol, v. 303, n. 2020, p. 479-502, 2020.

MOORE, Christopher W. The mediation process: Practical strategies for resolving conflict.John Wiley \& Sons, 2014.

PINHO, Humberto Dalla Bernardina de; MAZZOLA, Marcelo. Manual de mediação e arbitragem. São Paulo: SaraivaJur, 2019. 
RODRIGUES, Tereza Cristina T. S. Alternativas consensuais de resolução dos conflitos tributários no direito brasileiro: perspectivas à luz do princípio da legalidade. 2009.

ROEBUCK, Derek. The myth of modern mediation. Arbitration: the Journal of the Chartered Institute of Arbitrators, v. 73, n. 1, p. 105-116, 2007.

SCHABBEL, Corinna. Mediação corporativa. 2007.

SILVA, Alessandra Vick Coelho da. MEDIAÇÃO AMBIENTAL. Tese de Doutorado. Universidade de Coimbra. 2017.

SIVIERO, Karime Silva. Aspectos polêmicos da mediação judicial brasileira: uma análise à luzdo novo código de processo civil e da lei da mediação. Cadernos do Programa de PósGraduação em Direito-PPGDir./UFRGS, v. 10, n. 3, 2015.

TJ-AL. Tribunal de Justiça de Alagoas. Líderes comunitários são capacitados na mediaçãode conflitos. 2017. Disponível em:

https://www.tjal.jus.br/comunicacao2.php?pag=verNoticia\&not=11927. Acesso em $03 \mathrm{dez}$ 2020. Acesso em 25 nov. 2020. 